\title{
Global Engineering at the University of Iowa: Connecting Engineering Students With the World
}

Zach Smith, Program Coordinator and Advisor, University of Iowa International Programs Amy Brewster, Director of Global Experiences and Academic Advisor, University of Iowa College of Engineering Megan Allen, Registrar, University of Iowa College of Engineering

\section{Goal to Increase Global Exposure Among Engineering Students}

The University of Iowa, College of Engineering mission is "to serve the state, the nation, and the world by graduating talented, broadly educated engineers, conducting high quality research, developing new technologies, and creating, disseminating and preserving knowledge.”1

Increasingly, engineering graduates will be expected to have some level of global competence, as "the engineers who will be the leaders of the future will often manage and direct global engineering activities."2 Some of the most valuable characteristics of global competence among engineering graduates include:

1. Can appreciate other cultures.

2. Are proficient working in or directing a team of ethnic and cultural diversity.

3. Are able to communicate across cultures.

4. Have had a chance to practice engineering in a global context, whether through an international internship, a service-learning opportunity, a virtual global engineering project or some other form of experience.

5. Can effectively deal with ethical issues arising from cultural or national differences. ${ }^{2}$

Learning abroad experiences can help engineering students develop some or all of these characteristics of global competence. In fact, providing students with global opportunities is becoming increasingly important, as it is very likely that, regardless of discipline, engineering graduates will interact with customers and colleagues across the globe. ${ }^{3}$ "Because engineering graduates are very likely to work on international teams performing research and development, design, manufacturing, etc., they need exposure to other cultures and languages during their undergraduate career to help them better understand cultural differences."3 A growing number of postsecondary STEM (science, technology, engineering, and mathematics) programs are investing in learning abroad opportunities for students, and for some, global experiences for students is seen as not only preferred, but expected. ${ }^{4}$

In 2010, the College of Engineering created a strategic plan for academic years 2010-2016. Nine strategic initiatives were identified, two of which include goals related to the promotion and support of global learning opportunities for students:

1. Strategic initiative: Undergraduate Student Success, which includes goal to "Promote and support global learning opportunities for undergraduate students, including study-abroad experiences and international service learning experiences.” 1 
2. Strategic initiative: Internationalization and Diversity, which includes goal to "Promote and develop study abroad opportunities for undergraduates."

Additionally, aligning specific goals set by ABET Student Outcomes drives the college to continue to grow and increase the global experiences for their students. The College of Engineering continually seeks global opportunities and problems to bring to the classroom in addition to promoting opportunities to learn outside the classroom to gain real-world experience.

\section{Collaboration Between College of Engineering and International Programs}

The College of Engineering has found an excellent partner in the International Programs office at the University of Iowa. The International Programs office houses two units: Study Abroad and International Student and Scholar Services (ISSS). Early in 2014, stakeholders from both the College of Engineering and International Programs met to discuss plans to work together to support the goal of increasing participation in learning abroad experiences among engineering students. Senior leaders from both organizations were present, thereby providing an additional level of support and commitment to the partnership and overall goal. The initial meeting also afforded the opportunity for staff members from both organizations to make connections and to lay the groundwork for future working relationships.

\section{Our Approach}

A framework was developed early on to help guide our efforts of increasing participation in learning abroad experiences among engineering students. The graphic below (Figure 1) provides an overview, followed by a detailed description of each component.

\section{Determine Current State}

Study Abroad collects institutional data from all students who express interest (by swiping their University ID card at a fair and/or at the Study Abroad resource room) in studying abroad, apply for a University of Iowa study abroad program online, and/or participate in a University of Iowa sponsored, and/or non-sponsored study abroad experience. This data is collected via a custom built database built by the University of Iowa ITS department, which enables Study Abroad to tap into various institutional databases/data warehouses. Each student who is entered into the Study Abroad database is assigned a unique "card" which both displays these various sets of information, and also tracks their interactions with Study Abroad.

In order to determine the current state of both programs on offer for College of Engineering students, and also who participates in them, it was decided that Study Abroad would comb through all relevant collected data with College of Engineering markings. The search would be for all engineering students who both participated in study abroad programs (including those who also went abroad under the auspices of the University of Iowa for international internships, research, etc.), and who also expressed interest in studying abroad, but did not. Both data sets would then be measured on a percentile basis against other colleges at the University of Iowa for overall study abroad participation metrics. 
Figure 1. Global Engineering Framework

\section{Determine Current State}

-Benchmark data

- Inventory of current offerings, partners, promotion

strategies, student support

\section{Create Global Engineering Package}

-Focused, targeted offerings (with an eye on quality, accessibility, affordability)

-Major-specific (one size does not fit all)

- Collaboration with departmental leaders

\section{Create Global Engineering Infrastructure}

- Partnerships within Engineering and across campus

- Streamlined process for students; removal of barriers

- Scholarship funding

\section{Promote the Global Engineering Package \\ -Brand Global Engineering Package \\ -Multiple channels/methods \\ - Consistent messaging}

\section{Celebrate the Global Engineering Experience}

-Recognize students and partners

- Evaluate efforts to celebrate successes and find areas for improvement

It is important to note that University of Iowa students (undergraduate, graduate, professional degree students, residents and fellows) are only required to register their international travel to the University of Iowa if they are traveling for University of Iowa related purposes. While the University of Iowa and the College of Engineering are interested in both tracking and promoting other forms of international travel, the scope of data collection is limited and can only provide data for those students who have registered their travel as relating to their purposes at the University of Iowa. 
Once the aggregate data for engineering students traveling abroad for University of Iowa purposes was collected (2010-2011), the particular identity and academic fields for each student could be filtered into various sets. The two initial sets were:

1. Overall engineering participation

2. Participation by major (i.e., Biomedical, Chemical, Civil, Electrical, Industrial, Mechanical, Undeclared and double majors)

For the first set, it was determined that $4.4 \%$ of University of Iowa Engineering students studied abroad in 2010-2011, which was .3\% behind the national average according to NAFSA (Association of International Educators) statistics during that same time period. ${ }^{5}$

Upon further segmentation, the data showed that University of Iowa's greatest participation abroad by engineering departments were ranked as:

1. Civil Engineering (39 participants)

2. Industrial Engineering (tied for $2^{\text {nd }}$ with 29 participants)

2. Mechanical Engineering (tied for $2^{\text {nd }}$ with 29 participants)

3. Biomedical Engineering (28 participants)

4. Chemical Engineering (16 participants)

5. Electrical Engineering (11 participants)

6. Undeclared (8 participants)

With firm data sets for these two questions in hand, more specific questions could now be created within a framework to start realizing the actual state of Global Experiences for the College of Engineering and its students. This gave way to the second round of inquiry, which focused on the following program-specific questions in order to get more specific details:

1. Which countries did students travel to for study?

a. What were the specific participations for the individual departments for each country?

2. During which terms (Fall, Winter, Spring, or Summer) did students study?

a. What were the specific participations for the individual departments for each term?

3. Which programs did the students attend?

a. What were the specific participations for the specific programs for each department?

4. What types of programs were attended?

a. Consortium member, University of Iowa as lead administrator in consortium, member institution, University of Iowa exchange, University of Iowa program, or non-University of Iowa program?

At this point, data were arranged to demonstrate which programs had the highest amount of participation, which sessions students studied during, and generally on what type of program they were going on. It became immediately apparent, however, that even this scope was too 
limited because it neither included detailed program specific matter, not demographic information regarding the participants.

Therefore, a final round of queries were formulated to extract further qualifiers for the program data, as well as incorporate an element of student demographics.

- Programs:

o Were most programs participated in either long or short-term (i.e. summer vs. semester and academic year)?

o Are the programs in English or in the host language?

o How many credits were the average short-term programs?

o Were the University of Iowa sponsored programs aligned with the College of Engineering with a standing MOU or Exchange Agreement?

- If yes, which ones?

- If not:

- Where other similar programs participated in?

- Where programs in same location participated in?

- Timing:

o For longer term programs (semester and academic year), was there a particular semester that was more often utilized for study abroad?

- Was there any trend throughout the various departments, or did participations vary?

o Did students who studies abroad graduate on time?

- Subject Matter:

0 Did students study engineering?

- If so, did they do so in English or the host language?

- If not, what did they take?

o How many students were working on minors?

o How many students studied a foreign language?

o How many students simply received electives?

0 Do all of these questions have the same or different answers depending on short vs. long term programs?

- Students:

o Male vs. Female

o Residents vs. Non-Residents

o Grade Level

o Ethnicity

When these data sets were collected, initial questions started to be answered, and ever more questions started to arise. To provide a basic sense of the data collected, it can be shared that over the course of three academic years, the college of engineering had:

1. 160 total participants on $60+$ various programs

2. Top destinations were:

a. France (short-term)

b. India (short-term) 


\section{c. UK (long-term)}

3. $75 \%$ of the participants participated on short-term programs (i.e. summer or winter)

When filtering these initial findings even further with the queries above, it was discovered that only $15 \%$ of the programs (2 long-term, and 7 short-term) had repeat participation of four or more students. Both long-term programs were non-engineering specific programs, whereas six of the seven short-term programs were directly related to engineering. The top participated shortterm program was, however, a faculty-led program by the College of Engineering, which accounted for almost $15 \%$ of total study abroad participations from College of Engineering students.

Regarding the inventory that was taken that specifically related to College of Engineering sponsored/affiliated programs, it was found that the College of Engineering itself has four active department specific exchange agreements, twelve Memorandums of Understanding, four dual degree programs and two formal (institutional agreement) collaborative agreements.

Out of the 22 active relationships that the College of Engineering has, only two students utilized a summer exchange program. Discovering these numbers eventually will lead to questions outside of the scope of this initial inquiry, but will be integral when discussing resource appropriation.

As far as the demographics of participants are concerned, the following is what was found:

1. Male and Female participation was equal

2. Residents and Non-resident participation was equal

3. Regarding ethnicity, below are the self-disclosed ethnic representations:
a. $64 \%$ Caucasian
b. $14 \%$ Asian
c. $11 \%$ Latino
d. 3\% African American
e. $6 \%$ International Students (no ethnicity recorded)
f. $2 \%$ non-disclosed

4. Regarding participants grade level at the time of study abroad, there were:
a. 6\% Freshman
b. $42 \%$ Sophomore
c. $31 \%$ Junior
d. $21 \%$ Senior

\section{Conclusion of Initial Findings}

Overall, the data collected is extremely useful for both the evaluation of past programs, and also the creation of future strategies. While discovering that only $1 \%$ of total participation in Study Abroad programs were in official exchange programs sponsored by the College of Engineering with its foreign institutional partnerships is an important indicator, it is also just as important to note that a single faculty led program accounted for $15 \%$ of total participations. 
When looking at the promotional materials for the College of Engineering programs, they were either out of date, or non-existent. There were also few specific promotions or orientations for these programs. Higher trafficked programs had current promotional material, orientations, and/or direct faculty involvement.

These findings coupled with the numbers seemed to clearly indicate that there is a lack of focus regarding study abroad programs for College of Engineering students, which creates inefficiencies -in both Study Abroad and the College of Engineering.

There is also both an underutilization of existing programs housed under the College of Engineering, as well as a lack of understanding of which programs students would even prefer to go on. Therefore, the next step in the process was to evaluate the existing programs to determine a focus for future promotion.

\section{Evaluation of Existing Programs}

This next step was by far the most time consuming, as it involved a complete audit of all of the University of Iowa's exchange programs. For the sake of brevity, it was found that out of all potential semester and summer exchange based programs, 18 were deemed to have engineering programs that would at least offer courses comparable to those at the University of Iowa's College of Engineering.

These 18 programs were then broken down into engineering departments, to see if they would align with the University of Iowa's engineering departments - criteria was for the partner university to have 5 of the 6 same departments. 11 programs had 5 of the 6 departments, and out of the 11, three were actually sponsored by the University of Iowa's College of Engineering. All 11 programs were either ABET accredited, or were accredited in systems recognized by the Washington Accord.

We then took the 11 programs and researched each department to determine whether their curriculum and courses on offer matched the University of Iowa's College of Engineering, and if so, which language they were offered in, and whether they would be able to be regularly offered to University of Iowa participants.

After completing this complete audit, five specific partners were identified where it was decided to narrow the focus. They were:

1. Newcastle University - Australia

2. Hong Kong University of Science and Technology (HKUST) - Hong Kong

3. Bogazici University - Turkey

4. Swansea University - Wales, UK

5. American University of Sharjah - United Arab Emirates

All five partners featured accredited (either ABET or Washington Accord recognized) programs taught exclusively in English. Out of these five partners, only HKUST was officially sponsored by the College of Engineering though. It was decided to focus initially on these five partnerships because of the English factor, and that they represent diverse geographical locations. Not only do 
they represent diverse locations, but also are in locations that house branches/offices of the University of Iowa's College of Engineering top employment recruiters for its graduates.

A final step of the audit also included cost comparisons. Therefore, the standard University of Iowa semester tuition for engineering majors in their second year (as this is when the majority of students went) was used as a benchmark: $\$ 4,665.50$ for residents and $\$ 14,358.50$ for nonresidents (plus $\$ 6,000$ for housing). Comparatively, it was found that the five programs had the respective tuition (and sometimes inclusive of housing):

- HKUST (same as it is an exchange)

a. $\$ 4,665.50$ for residents and $\$ 14,358.50$ for non-residents (plus $\$ 750$ for housing)

- Bogazici (same as it is an exchange)

a. $\$ 4,665.50$ for residents and $\$ 14,358.50$ for non-residents (plus $\$ 3,500$ for housing)

- Newcastle

a. $\$ 8,476$ for residents and $\$ 10,120$ for non-residents (plus $\$ 6,300$ for housing)

- Swansea

a. $\$ 11,776$ for residents and $\$ 13,372$ for non-residents (housing included)

- American University of Sharjah

a. \$14,900 for both residents and non-residents (housing included)

With this comparison, it became clear that both residents and non-residents had either cost comparable options, or in a few cases cheaper options to study abroad than to stay on campus. Residents would be limited in the perspective of cost to HKUST and Bogazici, or could decide to spend more for a different location. Non-residents would always be spending less money than staying on campus in terms of housing and tuition.

\section{Conclusion of Evaluation of Programs}

It was very surprising to find that there were so many English-taught options within accredited programs for engineering students. Furthermore, these findings proved to dispel the myth of study abroad being expensive (at least for long-term options), and out of reach for engineering (and STEM) students. After intensive curriculum review, the College of Engineering at the University of Iowa will also be accepting the majority of courses as direct equivalents for required major coursework at the University of Iowa.

At this point, it is much easier to see where the state of global experiences stand for engineering majors and the department itself. The various sets of data point toward a wide array of options, with many being cost-effective and curricula correct for the long-term, but there was a general lack of focus and organization, which led to inefficiencies.

\section{Determining Desired State - Creating the Global Engineering Package}

Efforts to promote learning abroad to engineering students have been packaged under the title Global Engineering. The idea behind Global Engineering is that engineering students are provided with some targeted learning abroad opportunities (with flexibility to explore beyond the 
targeted programs), coupled with support and encouragement to incorporate a global experience in their undergraduate career.

It is important to note that these targeted opportunities will by no means be the exclusive options for global experiences open to College of Engineering students. Students will still be able to engage in any global opportunity that is available to them and encouraged to do whatever is right for them and fits in with their academic and career goals. The targeted opportunities will simply focus on engineering focused experiences, primarily in longer-term settings (semester or academic year) with a few engineering specific short term option in the winter and summer.

As noted in the evaluation of current programs, the evaluation process naturally selected a few candidates to be focused programs due to their offerings, locations, cost and instruction language. It became clear though, that these programs needed further focus. Therefore a plan was created to become masters of a specialized set of programs. Instead of putting all options on the table for the students and not being able to allocate sufficient resources to create promotional materials, provide course evaluations, build partnerships, and target needs, it was decided to focus on four programs as a pilot. Students were and are still able to participate in any program that they find, however, these four programs will be completely vetted by the College of Engineering and be the ones that are internally promoted.

This movement away from a "one-size-fits-all” approach to a more tailored selection of programs will better meet the needs of the engineering students in each department. This will be assured through a vetting process that meets all of the College of Engineering's academic standards, as well as the University of Iowa's health and safety standards.

The four programs will all feature a wide-array of pre-approved courses that are placed into an integrated curriculum map for each major. This will insure accessibility for all students in each department, whether they desire to study on a short and/or long-term program. Regarding accessibility, because the University of Iowa can devote more resources to these focused partnerships, a guaranteed number of places in specific, high-demand courses will be reserved for University of Iowa students, and enrollment process will easily be facilitated.

In order for this to properly function though, there needs to be buy-in from administration, department chairs, and faculty members, so that they can both see the value and also speak for the programs. Once the curriculum maps are integrated though, study abroad will no longer be a far flung idea, but a supported reality.

\section{Create Global Engineering Infrastructure}

Students need the tools and resources to explore Global Engineering options, and infrastructure must be in place to make the process as smooth as possible for students, staff, and faculty involved at various points throughout the process.

The College of Engineering and Study Abroad office have partnered to strengthen the infrastructure that supports learning abroad opportunities for engineering students. Current and future efforts include: 
- The creation of major-specific Major Advising Page Web content that helps students, faculty, and staff understand various aspects of learning abroad, including: general information about the academic discipline related to global experiences, tips on timing learning abroad experiences, curriculum considerations, funding opportunities, and a list of highlighted programs to explore. ${ }^{6}$

- Better promotion of College of Engineering Study Abroad Scholarships through Web content, fliers, and promotional events.

- Pre-approved courses from the four targeted institutions to assist students and faculty to research courses to match program and curricular needs.

- Changed curriculum maps to include learning abroad options, providing a visual for students and advisors to see recommended times and program options to go abroad.

- Continuous collaboration with the Study Abroad office to combine resources to reach students and assist faculty and staff advisors in understanding and providing support throughout the process of students exploring Global Engineering opportunities.

- Simplification of the process followed by students, from the time they start to explore Global Engineering opportunities through returning home from their global experience. Staff and faculty in both the College of Engineering and the Study Abroad office should be aware of this process in order to minimize unnecessary referrals between organizations. The process for students is as follows:

- Students are encouraged to participate in a Global Engineering experience through variety of methods, including "Lunch and Learn" information sessions; advising appointments; Web content, and visits by Study Abroad students/staff to classrooms and student organization meetings.

- Students meet with their faculty or academic advisor to discuss timing and decisions about whether or not to incorporate engineering coursework into their learning abroad experience.

- Students meet with a peer assistant in the Study Abroad Resource Room to further explore options with respect to: program type (i.e., study, volunteer, internship), program length, timing, location, cost, and scholarship/fellowship opportunities.

- Students meet with a Study Abroad advisor to further refine goals related to a Global Engineering experience.

- Students apply to their program of interest, as well as any scholarship or fellowship opportunities relevant to that program. For study abroad experiences, students also complete a Course Approval Form to determine course equivalencies as necessary.

- Students participate in relevant orientation sessions and Study Abroad advisor meetings prior to departure.

- Students complete their Global Engineering experience.

\section{Promote the Global Engineering Package}

A sustained effort to promote the Global Engineering package will be needed to encourage participation in learning abroad, as well as to dispel the commonly held myth that engineering students cannot go abroad due to typically demanding curricula. To build familiarity with the concept of Global Engineering, a graphic was created which will be used on relevant Web pages, posters, fliers, and other communications used to promote learning abroad opportunities to 
engineering students. Over time, students, staff, and faculty will become familiar with the Global Engineering graphic, and come to associate it with communications related to learning abroad.

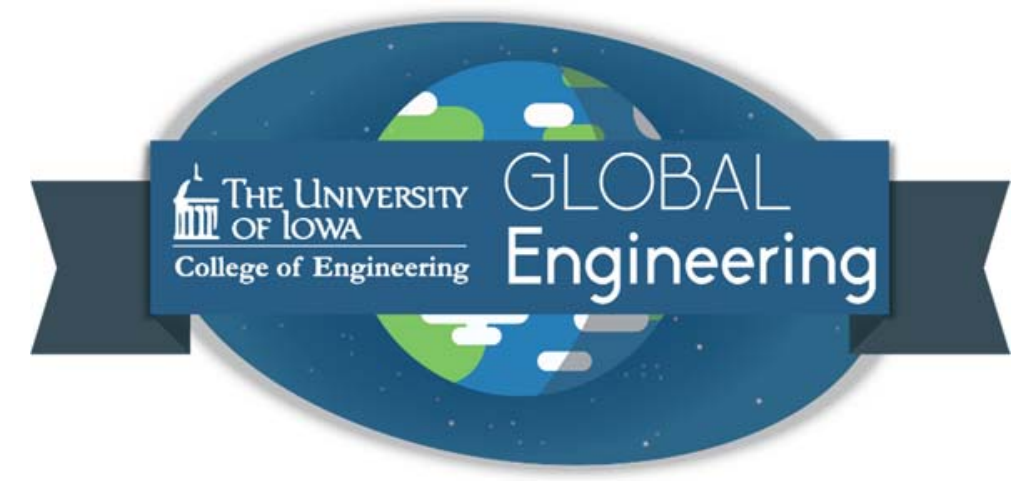

Initial and future efforts to promote Global Engineering will incorporate multiple channels and methods. We plan to consistently communicate these messages to engineering students:

- Engineering students CAN incorporate a global experience in their undergraduate career.

- There are multiple programs with flexible options to explore with regard to program type, length, location, cost and timing.

Promotion of Global Engineering will be directed at faculty and staff within the College of Engineering, so they have the knowledge and tools they need to support students' interest in learning abroad. Three upcoming events will serve as opportunities to reach faculty and staff: 1) new faculty orientation; 2) a retreat for departmental staff; and 3) departmental faculty meetings in the fall.

Efforts have been made to promote Global Engineering opportunities directly to students. Inperson efforts include a series of "Lunch-and-Learn" events, in which students are invited to hear from a speaker about a learning abroad-related topic while enjoying free lunch. Required courses such as departmental seminars have been targeted for in-person promotion, where a staff member has anywhere from 10-20 minutes to talk about opportunities to study, volunteer, intern, or work abroad. Global Engineering is a highlighted topic during student orientation for both incoming first-year and transfer students. Global Engineering is also represented at both the fall and spring Study Abroad Fairs held on campus. At the time of writing this paper, Global Engineering Web content is under development for both the College of Engineering Web site, as well as the Office of Study Abroad Web site. Once completed, students should be able to easily navigate a menu of options and find information about learning abroad that is relevant to their specific engineering major. Email has been utilized to promote global opportunities to engineering students, and we hope to utilize social media in the near future.

\section{Celebrate the Global Engineering Experience}

It will be important to celebrate the successes of Global Engineering over time. We have begun to collect student photos, testimonials, and profiles to feature online and through social media. We plan to recognize and cultivate positive working relationships with our partners across campus and abroad, as well as to evaluate efforts to determine areas for improvement. 


\section{Bibliography}

1. College of Engineering (n.d.). College of Engineering strategic plan academic years 2010-2016. Retrieved from https://www.engineering.uiowa.edu/sites/default/files/files/2010-2016-strategic-plan.pdf

2. Parkinson, A. (2009). The rationale for developing global competence. Online Journal for Global Engineering Education, 4(2). Retrieved from http://digitalcommons.uri.edu/ojgee/vol4/iss2/2

3. Bremer, D. (2008). Engineering the world. Online Journal for Global Engineering Education, 3(2). Retrieved from http://digitalcommons.uri.edu/ojgee/vol3/iss2/2

4. Leggett, K. (2011). Encouraging STEM students to study abroad. International Educator, July August 2011. Retrieved from http://www.nafsa.org/_/File/_/ie_julaug11_edabroad.pdf

5. NAFSA (n.d). Trends in U.S. study abroad. Retrieved from http://www.nafsa.org/Explore_International_Education/Advocacy_And_Public_Policy/Study_Abroad/Trends_i n_U_S_Study_Abroad/

6. International Program (n.d.). Major advising pages. Retrieved from http://international.uiowa.edu/studyabroad/major-advising-pages 